\title{
O PRIMEIRO CAPÍTULO DO FOLHETIM DE CONY NO JORNAL ALTERNATIVO O SOL (1967) ${ }^{1}$
}

\author{
Leandro BRITO \\ Prof $^{\mathrm{a}} \mathrm{Dr}^{\mathrm{a}}$ Márcia Neme Buzalaf ${ }^{3}$ \\ Universidade Estadual de Londrina (UEL), Londrina, PR
}

\section{RESUMO}

O período da ditadura civil-militar durou mais de vinte anos no Brasil (1964-1985). O contexto histórico conturbado da época, devido à censura, à tortura e às perseguições, criou a situação propícia para o florescimento da imprensa alternativa. Os jornais alternativos tiveram uma relevância significativa naquele momento, principalmente porque exerceram um papel de resistência e combate ao regime militar. Neste contexto, o poeta, escritor e jornalista Reynaldo Jardim idealizou, no Rio de Janeiro, o jornal alternativo $O$ Sol (circulou entre setembro de 1967 e janeiro de 1968), em que o renomado escritor Carlos Heitor Cony publicava diariamente um folhetim no estilo policialesco. Por meio de uma leitura atenta das histórias, é possível perceber marcas do momento histórico em que os textos foram produzidos, além de apresentarem algumas construções linguísticas e textuais interessantes e propícias para estudo mais pormenorizado. Levando isso em conta, este artigo visa à análise do primeiro capítulo do folhetim A Sotaína Ensagüentada, publicado em 21 de setembro de 1967, usando como base os conceitos discursivos de Mikhail Bakhtin.

Palavras-Chave: Jornal $O$ Sol; Carlos Heitor Cony; Ditadura; Imprensa Alternativa; Mikhail Bakhtin;

\section{INTRODUÇÃO}

Foi em primeiro de abril de 1964 em que, dizendo-se preocupados com a instauração do comunismo no Brasil, os militares executaram o golpe militar que perduraria até o ano de 1985. Durante os mais de vinte anos em que o território brasileiro esteve no comando dos militares, a imprensa passou por grandes transformações. Neste período iniciou-se a criação, em diversas partes do Brasil, dos jornais alternativos. Essa nova imprensa que começou a pipocar, nos mais variados estados brasileiros, desempenhava o importante papel de trazer ao conhecimento público aquelas informações escondidas pelo governo. Durante este período, a imprensa alternativa foi a principal vítima da censura praticada por civis e militares. De acordo com Bernardo Kucinski (2003), no período que vai de 1964 a 1980, “nasceram e

\footnotetext{
${ }^{1}$ Trabalho apresentado no XI Seminário de Pesquisa em Ciências Humanas - SEPECH, 2016.

${ }^{2}$ Graduado do curso de Comunicação Social - Jornalismo da Universidade Estadual de Londrina (UEL). E-mail(s): leandro_brito91@hotmail.com; leandrobritolb91@gmail.com.

${ }^{3}$ Orientadora do trabalho.
} 


\section{SEMINÁRIO DE PESQUISA EM CIÊNCIAS HUMANAS - SEPECH \\ Humanidades, Estado e desafios didático-científicos \\ Londrina, 27 a 29 de julho de 2016}

morreram cerca de 150 alternativos que tinham como traço comum a oposição intransigente ao regime militar" (KUCINSKI, 2003, p.05).

Neste período, vários jornalistas sonharam com mudanças políticas e sociais no Brasil, mas, praticamente, não tiveram espaço para se expressarem, pois foram silenciados pela censura e pelo terrorismo disseminado não só pelo militares, mas também por setores da sociedade civil. Márcia Neme Buzalaf (2009), por meio de um gráfico (p.44), elaborado com base no livro de Bernardo Kuscinsk, Jornalistas e revolucionários - Nos tempos da Imprensa Alternativa, mostra que, de 1964 a 1980, nasceram 144 jornais alternativos, destes, 108 duraram menos de um ano. Entre esses jornais efêmeros, encontra-se $O \mathrm{Sol}$, que circulou no Rio de janeiro, entre setembro de 1967 e janeiro de 1968. O periódico era um jornal financiado pelo diretor do Jornal dos Sports e se diferenciava dos demais por ter uma circulação diária.

$O$ Sol foi idealizado pelo poeta, escritor e jornalista Reynaldo Jardim e tinha como proposta inicial criar um jornal-escola (jornal laboratório), quebrando aquele padrão da faculdade de jornalismo, que produzia um periódico de simulação para os estudantes de comunicação praticarem a produção jornalística. Importantes profissionais fizeram parte d'O Sol, como Ana Arruda Callado, Ziraldo, Zuenir Ventura, Arnaldo Jabor, Carlos Heitor Cony, Chico Buarque, Fernando Gabeira, Martha Alencar, Tetê Moraes, Dedé Veloso, Nelson Rodrigues, entre outros; muitos deles que mais tarde fizeram parte do Pasquim.

O periódico tinha uma abordagem diferente dos meios de comunicação tradicionais; suas páginas contavam com algo inovador: eram recheadas de cultura, de educação e de política. Seus criadores utilizavam de recursos cômicos para levar ao leitor as mais duras criticas sobre diversos assuntos. Ele alcançou grande impacto no meio jornalístico, com diagramação inovadora, opção pela linguagem informal e, principalmente, pelo trabalho pautado na liberdade. Com essas inovações, fez sucesso, tanto que, no período de auge, o jornal chegou a vender mais de 70 mil exemplares.

Este artigo pretende, com base em conceitos de Mikhail Bakhtin (2003), como dialogismo, polifonia, contextualização e pluriliguismo, fazer uma análise do primeiro capítulo do folhetim escrito por Carlos Heitor Cony, no jornal $\mathrm{O} S o l$; tendo em mente que todo texto é uma soma de pensamentos e de ideias que fazem parte de um contexto específico. Segundo Bakhtin (2003), "as concepções ideológicas também são interiormente dialogadas e no diálogo externo sempre se combinam com as réplicas internas do outro" (BAKHTIN, 2003, p.199). Portanto, pode-se dizer que o discurso é um emaranhado de vozes que se unem para compor a narrativa de um autor.

\section{ESCRITOR RENOMADO}

Carlos Heitor Cony, colunista da Folha de S. Paulo e quinto ocupante da Cadeira $\mathrm{n}^{\circ} 3$ da Academia Brasileira de Letras, nasceu no Rio de Janeiro, em 14 de março de 1926. A aproximação do autor a escrita ocorreu já na infância devido à dificuldade com a dicção de palavras - principalmente trocando o "g" pelo "d". De acordo com Cony, quando descobriu que escrevendo as outras pessoas não zombavam dele, ingressou no mundo das letras. Assim, foi o constrangimento da fala, que o levou a se debruçar e se apaixonar pela escrita, tanto que, aos 10 anos de idade, já escrevia seus primeiros contos e crônicas. Entretanto, a carreira de escrito de romance só foi 


\section{SEMINÁRIO DE PESQUISA EM CIÊNCIAS HUMANAS - SEPECH \\ Humanidades, Estado e desafios didático-científicos \\ Londrina, 27 a 29 de julho de 2016}

realmente concretizada anos mais tarde, no ano 1956, quando publicou o seu primeiro livro $O$ Ventre.

Aos 18 anos de idade, Cony ingressou no seminário, onde era o responsável pelas crônicas da paródia a qual fazia parte. Desde a infância nunca deixou de escrever e assim, diante de crônicas, ensaios e contos, o escritor foi aprimorando a escrita. No ano 1952, depois de abandonar o sonho de ser padre, entrou para trabalhar na redação do jornal Correio da Manhã, para cobrir férias do seu pai, que era jornalista. Assim, na prática, aprendeu o ofício do jornalismo e nunca mais deixou de escrever para um meio de comunicação.

Além de escritor renomado, dono de muitos prêmios importantes, com Machado de Assis, Jabuti, Manuel Antônio de Almeida, Cony teve uma participação muito efervescente na imprensa alternativa. Escreveu, por exemplo, para o Correio da Manhã e também para o jornal $O \mathrm{Sol}$. Embora tenha assumido uma posição crítica ao regime militar, em um texto publicado na Folha de S. Paulo, foi conivente com o golpe de 1964. Cony fez uso dos espaços editoriais para atacar tanto Jango Goulart como as reformas de base do presidente. De acordo com Silva (2014), "hoje romancista de renome, foi talvez o primeiro a compreender o tamanho do erro em que tinham se atolado, ele mesmo tendo ajudado, como se verá, a desqualificar Jango e o seu governo". (SILVA, 2014, p.8 e 9)

Cony, hoje escritor celebrado e colunista da Folha de S. Paulo, teria contribuído, segundo ele mesmo, cortando um parágrafo do texto e inserindo uma frase. Mera colaboração de colega. Rapidamente Cony se tornaria indenizado como perseguido político com uma polpuda aposentadoria. (SILVA, 2014, p.42)

Devido aos conteúdos de denúncia ao regime militar, Cony foi perseguido, preso e exilado. No entanto, nunca deixou de expressar as suas ideias e pensamentos por meio da escrita. Assim o escrito foi trilhando o seu caminho, que o levou a ser um dos escritores renomado do Brasil.

No jornal $O$ Sol, Cony trabalhou como editor da editoria de Polícia. Além desse cargo, tinha, no periódico, um espaço reservado para escrever um folhetim. Pertencente às páginas policiais, as histórias de Cony é tematicamente influenciado pela Editoria, visto que eram histórias de cunho policialesco. O capítulo da história analisado neste artigo foi publicado n'O Sol, no dia 21 de setembro de 1967, primeira edição do periódico.

\section{CONTEXTO HISTÓRICO, PLURILINGUISMO E POLIFONIA}

Ter acesso a um livro que tenha sido escrito há décadas ou séculos é uma experiência, no mínimo, diferente. Quando se analisa um material histórico, é necessário ter em mente que todo o discurso está impregnado de referências da época em que foi escrito. Segundo Bakhtin (1988), "estudar o discurso em si mesmo, ignorar a sua orientação externa é algo tão absurdo com estudar o sofrimento psíquico fora da realidade a que está dirigido e pela qual ele é determinado" (BAKHTIN, 1988, p. 99). 


\title{
XI SEMINÁRIO DE PESQUISA EM CIÊNCIAS HUMANAS - SEPECH \\ Humanidades, Estado e desafios didático-científicos \\ Londrina, 27 a 29 de julho de 2016
}

Por mais que às vezes possa não ser evidente, toda a constituição de um discurso é carregada de referência do contexto histórico no qual foi desenvolvido. A leitura de um romance deixa muito clara essa dependência estabelecida entre a composição textual é o momento histórico. Bakhtin (1988) afirma que "as diferentes pronúncias da palavra 'princípios' é um sinal que diferencia mundos histórico-culturais e sociais diferentes" (BAKHTIN, 1988, p. 99). Neste sentido, o autor ainda afirma que a linguagem, os jargões, o comportamento dos personagens e, até mesmo, os acentos são reflexo de uma época específica.

\begin{abstract}
A estratificação interna de uma língua nacional única em dialetos sociais, maneirismos de grupos, jargões profissionais, linguagens de gêneros, fala das gerações, das idades, das tendências, das autoridades, dos círculos e das modas passageiras, das linguagens de certos dias e mesmo de certas horas (cada dia tem sua palavra de ordem, seu vocabulário, seus acentos), enfim, toda estratificação interna de cada língua em cada momento dado a sua existência histórica constitui premissa indispensável do gênero romanesco. (BAKHTIN, 1988, p 74).
\end{abstract}

As marcas contextuais presentes em qualquer produção discursiva são orientadas por meio do que Bakhtin (1988) chamou de pluralinguismo social. Este termo que foi a base de outros dois conceitos trabalhados pelo autor: polifonia e dialogismo. De acordo com o pensamento bakhtiniano, todo o discurso, seja textual seja falado, é construído com base em diversas vozes que permeiam uma determinada sociedade. Assim, quando lemos um romance, por exemplo, não estamos apenas diante do posicionamento do escritor, mas também do contexto ao qual ele faz parte, ou seja, para Bakhtin (1988) "o romance é uma diversidade social de linguagens organizadas artisticamente, às vezes de línguas e de vozes individuais" (BAKHTIN, 1988, p. 74).

E é graça a este plurilinguismo social e ao crescimento em seu solo de vozes diferentes que o romance orquestra todos os seus temas, todo seu mundo objetal, semântico, figurativo e expressivo. O discurso do autor, os discursos dos narradores, os gêneros intercalados, os discursos das personagens não passam de unidades básicas de composição com a ajuda das quais o plurilinguismo se introduz no romance. (BAKHTIN, 1988, p 74).

Bakhtin (1988) deixar claro que basicamente todo texto é constituído por um emaranhado de vozes que se unem para compor o discurso de uma pessoa. Num primeiro momento, o discurso pode parecer uma composição autoral e original, porém tudo não passa de uma junção de princípios, costumes e visões de uma sociedade. Neste caminho, é possível destacar que todas as narrativas são apenas uma reprodução do que já foi dito por outro em algum momento - nada é original. Para Bakhtin (1988), Adão seria o único ser humano, de toda a história, a ter um discurso isento de marcas contextuais, pois, na história bíblica, ele foi o primeiro ser humano. Sendo assim, não tinha outras falas para basear o seu discurso. Mas depois dele, "qualquer discurso da prosa extra-artística - de costumes, retórica, da ciência - não pode deixar de se orientar para o ‘já dito', para o 'conhecido', para a 'opinião pública”' (BAKHTIN, 1988, p.88). 


\section{SEMINÁRIO DE PESQUISA EM CIÊNCIAS HUMANAS - SEPECH \\ Humanidades, Estado e desafios didático-científicos \\ Londrina, 27 a 29 de julho de 2016}

Diante do conglomerado de vozes usadas para tecer uma narrativa, pode-se dizer que todas as ideias que permeiam um discurso apresentam a opinião do autor. Neste sentido, no romance, os escritores usufruem de alguns recursos para propagar o seus pontos de vista e, assim, por meio das falas dos personagens ou fazendo uso da ironia e da comicidade, eles colocam em circulação aquilo que pensam. De acordo com Bakhtin (1988), tudo não passa de "uma construção híbrida análoga, onde a definição da opinião comum da sociedade mundana confunde-se com o discurso do autor, que denuncia a hipocrisia e o interesse dessa opinião comum" (BAKHTIN, 1988, p.113). O autor ainda afirma que,

O plurilinguismo também está disseminado no discurso do autor, ao redor dos personagens, criando as suas zonas particulares. Essas zonas são formadas a partir dos semidiscursos dos personagens, das diversas formas de transmissão dissimulada do discurso de outrem, a partir de palavras e pequenos termos espalhados no discurso de outrem, a partir da intrusão no discurso do autor de momentos expressivos alheios (reticências, interrogações, exclamações). Essa zona é o raio de ação da voz do personagem, que de uma maneira ou de outra se mistura com a do autor. (BAKHTIN, 1988, p. 120).

O diálogo, com a reflexão de Bakhtin (2003), nos permite ver que a linguagem de um romance é sempre impregnada de vozes, já que, ao representar uma dada realidade, ela é revestida de particularidades e de entonações que instauram as vozes de outros, vindas de diferentes esferas de atividade humana (política, religiosa, educacional, etc.). E é diante destes conceitos que este artigo pretende fazer uma análise do folhetim de Carlos Heitor Cony e, principalmente, entender como diferentes argumentos, ideias e pensamentos se escondem na narrativa de A Sotaína Ensangüentada.

\section{A SOÍTANA ENSANGÜENTADA}

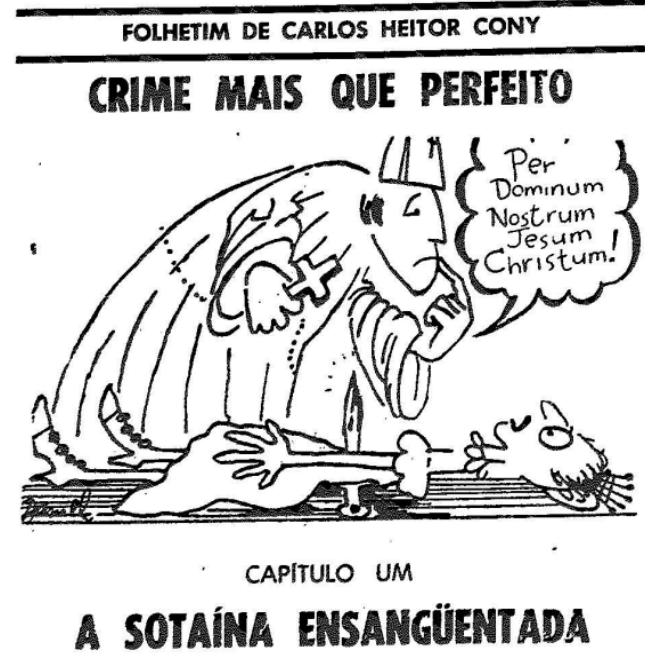

Figura 1: Primeiro capítulo do folhetim de Cony publicado na primeira edição do jornal O Sol, em 21 de setembro de 1967

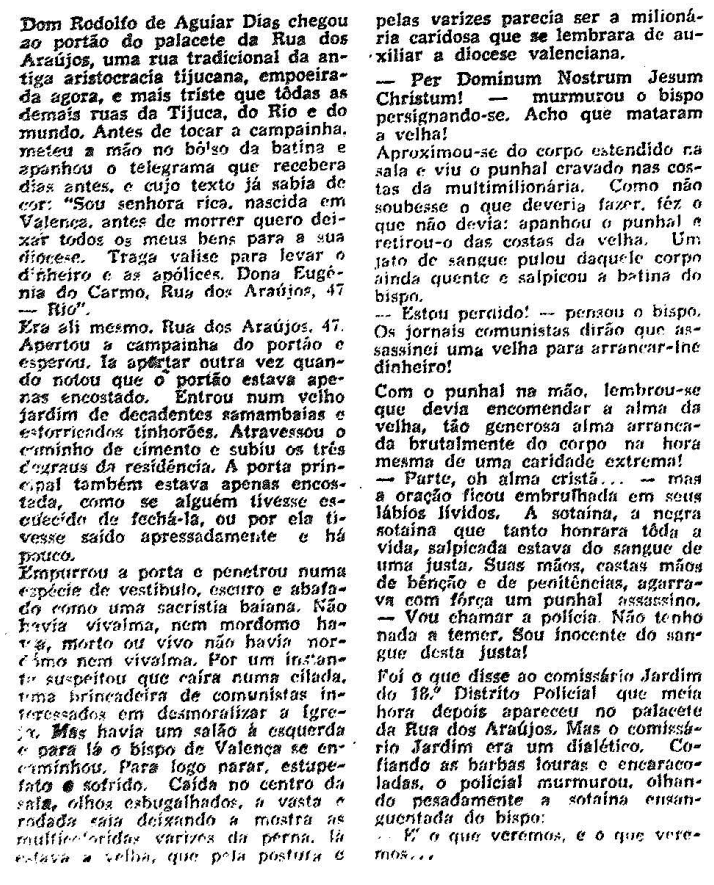




\section{SEMINÁRIO DE PESQUISA EM CIÊNCIAS HUMANAS - SEPECH \\ Humanidades, Estado e desafios didático-científicos \\ Londrina, 27 a 29 de julho de 2016}

O romance é uma diversidade social de linguagens organizadas artisticamente, às vezes de línguas e de vozes individuais. A estratificação interna de uma língua nacional única em dialetos sociais, maneirismos de grupos, jargões profissionais, linguagens de gêneros, fala das gerações, das idades, das tendências, das autoridades, dos círculos e das modas passageiras, das linguagens de certos dias e mesmo de certas horas (cada dia tem sua palavra de ordem, seu vocabulário, seus acentos), enfim, toda estratificação interna de cada língua em cada momento dado a sua existência histórica constitui premissa indispensável do gênero romancesco. (BAKHTIN, 1988, p 74).

A identificação das marcas do contexto no folhetim tem início no título do capítulo. As palavras "Sotaína", "vestíbulo", "vivalma" e "persignar" evidenciam essa peculiaridade. Além dos vocabulários característicos da época, a acentuação também, de certa forma, remete a década de 1967, quando as palavras "tôdas", "ensangüentada", "fôrça", "fêzz" eram acentuadas. Para Bakhtin (1988), toda a composição discursiva é influenciada pelo contexto o qual o autor faz parte. Com a leitura do folhetim de Cony não é diferente, pelo contrário está repleta de características que remetem a um contexto histórico social específico.

Em cada momento dado a coxistência línguas de diversas épocas e períodos da vida sócio-ideológica. Exitem até mesmo linguagens dos dias: com efeito, o dia sócio ideológico e político de "ontem" e de hoje não têm a mesma linguagem comum; cada dia tem a sua conjuntura sócio-ideológica e semântica, seu vocabulário, seu sistema de acentos, seu slogan, seus insultos e suas lisonjas. (BAKHTIN, 1988, p 98).

Em um contexto conturbado como a ditadura civil-militar brasileira, marcas historiográficas e ideias do período estão representadas na história de Cony. $\mathrm{Na}$ época do regime militar, era muito frequente os militantes, seguimento da sociedade contra $o$ regime, serem chamados de "comunistas". Aquino (2003) argumenta que "os chamados 'terroristas' e os genericamente conhecidos como 'comunistas', inimigos públicos do regime, foram alvos inegáveis de perseguição e não podiam ter divulgada a ação de sua repressão" (AQUINO, 2003, p.214). Ou seja, no período militar criou-se uma mentalidade muito forte que contribuiu com a taxação dos militantes de esquerda como "comunistas".

Para Aquino (2003), embora a Igreja Católica tenha apoiado os militares na aquisição de poder, "a partir de 1967, retiram o seu apoio posicionando cada vez mais na oposição" (AQUINO, 2003, p.73). Entretanto, há evidências no texto de Cony de que ainda existia, talvez não por todos, mas por uma parte da classe religiosa, um pensamento favorável ao regime. Kushnir (2004) ressalta isso ao afirmar que "a ação de setores mais conservadores da igreja, estavam ancoradas na vigília da 'mora e dos bons costumes" (KUSHNIR, 2004, p.146), e, assim, ao mesmo tempo em que propagava os pensamentos dominantes dos militares, incentiva o repúdio de pessoas que resistiam ao regime, ou seja, "no bojo dessa proposta, verdadeiro retrocesso, mais uma vez parcela 


\section{SEMINÁRIO DE PESQUISA EM CIÊNCIAS HUMANAS - SEPECH \\ Humanidades, Estado e desafios didático-científicos \\ Londrina, 27 a 29 de julho de 2016}

conservadoras da Igreja Católica protagonizaram o desfecho e revelaram sua força e prepotência em impor seus anseios" (KUSHNIR, 2004, p.150).

$\mathrm{Na}$ fala do personagem principal da história de Cony, é possível destacar o posicionamento que Kushnir (2004) defende em seu livro. Uma parte interessante para se destacar da história é a referência que o bispo faz sobre os "jornais comunistas", uma referência aos jornais alternativos, que, na época, assumia um papel muito forte de resistência. O autor coloca: "Por um momento suspeitou que caíra numa cilada, numa brincadeirinha de um comunista interessado em desmoralizar a igreja"(CONY, 1967); Depois na fala do personagem acrescenta "- Estou perdido! - pensou o bispo. Os jornais comunistas dirão que assassinei uma velha para arrancar-lhe o dinheiro!" (CONY, 1967). Essas ideias colocadas no texto de forma cômica e, ao mesmo tempo, irônica, era integrante do contexto da ditadura civil-militar brasileira. Isto é, foi constituído por meio das vozes do período, visto que não há enunciação sem troca, sem diálogo e não há diálogo sem contexto social.

No segundo momento em que a palavra comunista aparece, ela vem embutida da fala do bispo. Isso evidencia o posicionamento da igreja católica favorável ao regime militar. De acordo com Kushnir (2004), a igreja era capaz de fazer denúncias quando achava pertinente para a punição das pessoas que eram contra com regime. $\mathrm{O}$ apoio da igreja ao governo militar não ficaram claro apenas nas denúncias, visto que, como afirma Reis Filho (2002), a igreja, junto com outros grupos da elite brasileira, contribuiu com o golpe militar.

Outra evidência da configuração histórica social que aparece no texto é representada pela motivação que leva o bispo a ir até a casa da idosa caridosa, que é encontrada escancarada e morta com um punhal nas costas. Dom Rodolfo de Aguiar Dias vai até ao endereço para receber a doação das apólices da senhora. As ações e até mesmo as falas do bispo deixam evidente o interesse materialista da Igreja Católica no período.

Além disso, o autor tenta mostrar na fala do bispo que, mesmo de maneira implícita, a igreja tinha o costume de extorquir os fiéis. Fato que o próprio bispo evidencia ao dizer que os "jornais comunistas" - entende-se como os periódicos alternativos - diriam que ele teria matado a idosa para ficar com o dinheiro dela. $\mathrm{O}$ desenrolar da história sugere que bispo fosse inocente com relação ao assassinato da velha. No entanto, de forma implícita fica claro que a igreja não assumia a extorsão que realizava na sociedade. Com base nos argumentos de Bakhtin (1988), podemos dizer que o texto de Cony é "uma construção híbrida análoga, onde a definição da opinião comum da sociedade mundana confunde-se com o discurso do autor, que denuncia a hipocrisia e o interesse dessa opinião comum". (BAKHTIN, 1988, p.113).

É possível perceber, na narrativa, que Cony acrescenta ao seu romance pensamentos, ideologias e detalhes da ditadura. Dessa forma, o autor incorporou a histórias diferentes discursos sociais, criando o que Bakhtin (1988) chamou de plurilinguismo. Sendo assim, todo o texto não é uma construção ingênua e inocente. Cada palavra e sentido construído são pensados pelo escritor e ao transpor as ideias no papel, o autor acrescentou ao seu romance discurso de outrem, pois como afirma Bakhtin (1988) o autor "não pode esquecer ou ignorar de maneira ingênua ou convencional as línguas múltiplas que o circundam” (BAKHTIN, 1988, p.134) 


\section{SEMINÁRIO DE PESQUISA EM CIÊNCIAS HUMANAS - SEPECH \\ Humanidades, Estado e desafios didático-científicos \\ Londrina, 27 a 29 de julho de 2016}

Introduzido no romance, plurilinguismo é submetido a uma elaboração literária. Todas as palavras e formas que povoam a linguagem são vozes sociais e históricas, que lhe dão determinadas significações concretas e que se organizam no romance em um sistema estilístico harmonioso, expressando a posição sócioideológica diferenciada do autor no seio dos diferentes discursos da sua época. (BAKHTIN, 1988, p. 106)

Em A Sotaina Ensagüentada, os discursos sociais são colocados na crônica, principalmente, por meio das falas do bispo e seu comportamento. E assim, o autor vai cruzando informações e falas da sociedade que evidenciam o comportamento da sociedade, das instituições e, até mesmo, o ponto de vista do autor, uma vez que ele faz uso da ironia, da paródia e do humor, na confecção da sua narrativa. Neste sentido, como afirma Bakhtin (1988), "o discurso se encontra com o discurso de outrem e não pode deixar de participar, com ele, de uma interação viva e tensa." (BAKHTIN, 1988, p.88). Tensa porque nem sempre o que o autor coloca é o que ele pensa. Assim no texto, é criado um combate, entre vozes, muitas vezes, contrastantes, que Bakhtin (1988) chama de polifonia, embate entre diferentes vozes que habitam a narrativa de um discurso.

No romance aqui analisado a polifonia se materializa no texto, por meio da ironia, pois de acordo com Brait (2012), toda narrativa irônica é, por natureza, polifônica. A maior ironia de Cony ao escrever o primeiro capítulo de Um crime quase perfeito está caracterizada pela desconfiança do bispo, quando supõem ter sido enganado pelos "jornais comunistas". Essa passagem com traço humorístico traz à tona o paradoxo entre a realidade do escritor e a fala do personagem, visto que o autor trabalha em um jornal alternativo, supostamente, taxado de "comunista", e o folhetim também era publicado neste periódico. Sendo assim, a narrativa de Cony, com base na ironia, "apresenta diferentes vozes sociais que se defrontam, se entrechocam, manifestando diferentes pontos de vistas sociais sobre um mesmo objeto" (BRAIT, 2012, p. 25).

O pensamento bakhtiniano concebe, de um lado, a dialogia como princípio constitutivo da linguagem e como condição de sentido de todo e qualquer discurso, de outro lado, a polifonia, como um efeito de sentido decorrente de procedimentos discursivos ligados ao discurso literário. Como inerente a toda criação discursiva, observamos o princípio dialógico instanciado na interação entre sujeitos, pelo embate de muitas vozes sociais que se deixam entrever nas diferentes manifestações verbais. Conforme as estratégias discursivas acionadas, a obra literária pode produzir efeitos de sentido de polifonia, em que aparece esse embate de vozes, ou de monofonia, em que as vozes se ocultam atrás de uma única voz. (ZONIN, 2006, p.5)

No texto de Cony, com a junção da plurilinguismo, da polifonia e da contextualização, é possível perceber que muitas vozes são juntadas em uma mesma narrativa para desenvolver novos pensamentos e, ao mesmo tempo, eternizar diferentes discursos sociais em um texto, pois, como afirma Bakhtin (1997), não há enunciação sem troca, sem diálogo e não há diálogo sem contexto social. 


\section{SEMINÁRIO DE PESQUISA EM CIÊNCIAS HUMANAS - SEPECH \\ Humanidades, Estado e desafios didático-científicos \\ Londrina, 27 a 29 de julho de 2016}

\section{CONSIDERAÇÕES FINAIS}

Durante os 21 anos que o território brasileiro esteve no comando da ditadura, a imprensa sofreu grandes transformações. Com a instauração do regime militar nem tudo o que antes os meios de comunicação poderiam reportar era permitido - como mostra Beatriz Kushnir (2004), tudo, antes de ser divulgado, precisava passar por aprovação. Aos poucos, para controlar as notícias que iriam ser estampadas nos jornais, foi instituída a censura e posteriormente o terrorismo contra as empresas de comunicação.

Neste periódo diversos trabalhos interessantes foram desenvolvido, principalmente, na imprensa alternativa. Dessa forma é possível de depreender que tudo o que foi produzido durante o momento da ditadura civil-militar brasileira, direta e indiretamente, tiveram influência do contexto histórico da época, ou seja, em todo o discurso passado apresenta marcas textuais de outrem no momento de ser construir um novo.

Este artigo analisou, por meio dos conceitos baktinianos de plurilinguismo, de polifonia e de contexto social, o primeiro capítulo do folhetim, escrito por Carlos Heitor Cony, no jornal $O$ Sol. Por meio dos apontamentos, foi possível perceber que o contexto social o qual a narrativa foi escrita têm diferentes marcadas discursivas do momento histórico do autor e, ao mesmo tempo, apresenta um embate de vozes, tudo isso contribuiu para a construção discursiva da narrativa de $A$ Sotaína Ensangüentada.

Por meio das observações apontadas no folhetim de Cony, foi possível perceber que as falas dos personagens, a narrativa, o vocabulário, a acentuação das palavras são consideradas referência para determinar momento histórico do romance. Todas essas marcas só foram possíveis serem destacadas, pois foi baseado na teoria de Mikhail Bakhtin.

É interessante ressaltar que embora o presente estudo tenha se desdobrado em cima de uma obra específica, por meio dele fica claro que todo o discurso apresenta marcas do contexto histórico no qual ele foi escrito.

\section{REFERÊNCIAS}

AQUINO, M. A. Censura, Imprensa, Estado autoritário (1968-1978). Bauru: EDUSC,1999.

BAKHTIN, M. O discurso no romance. In:Estética da criação Verbal. 2. Ed. São Paulo: Martins Fontes. Cap. p. 71-164.

BAKHTIN, M. Problemas da poética/Mikhail Bakhtin. Trad. De Paulo Bezerra 2.ed - Rio de Janeiro: Forense Universitário, 1997.

BAKHTIN, M. Estética da criação verbal/Mikhail Bakhtin; introdução e tradução do russo Paulo Bezerra; prefácio à edição francesa Tzvetan Todorov. - 4.ed - São Paulo: Matins Fontes, 2003.

BRAIT, B. Bakhtin: outros conceitos-chaves/ Beth Braid, (org). 2.ed. - São Paulo: Contexto, 2012. 


\section{SEMINÁRIO DE PESQUISA EM CIÊNCIAS HUMANAS - SEPECH \\ Humanidades, Estado e desafios didático-científicos \\ Londrina, 27 a 29 de julho de 2016}

BUZALAF, M.N. A censura no Pasquim (1969-1975): as vozes não-silenciadas de uma geração. 2009. 220 f. Tese (Doutorado em História) - Faculdade de Ciências e Letras, Universidade Estadual Paulista, Assis. 2009

KUCINSKI, B. Jornalistas e Revolucionários: nos tempos da imprensa alternativa. São Paulo: EdUsp, 2003.

REIS FILHO, D. A. Vozes silenciadas em tempo de ditadura: Brasil, anos de 1960. In.:CARNEIRO, Maria Luiza Tucci (org.).Minorias Silenciadas: História da Censura no Brasil. São Paulo: Editora da Universidade de São Paulo / Imprensa Oficial do Estado / Fapesp, 2002.p. 435-450.

SILVA, J.M. 1964: golpe midiático-civil-militar. Porto Alegre: Sulina, 2014.

1. Fonte primária

Jornal $O$ Sol, edições 01 e 02. Rio de Janeiro, setembro de 1967. 